\title{
Combustibles alternativos en motores de combustión interna'
}

\author{
Juan Carlos Goñi Delión* \\ Mario Rojas Delgado* \\ Universidad de Lima. Lima, Perú
}

Recibido: 30 de abril de 2014 / Aprobado: 26 de junio de 2014

\begin{abstract}
Resumen: Este artículo explica el efecto de mezclas de combustible convencional con mayor concentración de biocombustible en motores de combustión interna. Los parámetros de operación de un motor de combustión interna fueron medidos mediante un freno de corrientes parásitas y equipo auxiliar. Se hicieron pruebas con mezclas de gasolina-alcohol carburante en un motor de ciclo Otto y de petróleo diésel-biodiésel en un motor de ciclo Diesel. Los resultados de la medición de los parámetros fueron analizados y se concluyó que un mayor contenido de biocombustible en las mezclas produce leve efecto en los valores de los parámetros del motor.
\end{abstract}

Palabras clave: petróleo diésel / gasolina / biocombustible / motor

\section{Alternative fuels in internal combustion engines}

AвSTRACт: This paper explains the effect of blends of conventional fuel with higher concentration of biofuel in internal combustion engines. The operational parameters of an internal combustion engine were measured by means of a parasitic current brake and auxiliary equipment. Tests were made with blends of gasoline-carburetting alcohol in an Otto cycle engine; and with blends of fuel oil-biodiesel, in a Diesel cycle engine. The results of the measurement of the parameters were analyzed, and the conclusion was that a higher concentration of biofuel in blends produces slight effect in the engine parameter values.

Key words: fuel oil / gasoline / biofuel / engine

1 Este artículo se basa en los resultados de la investigación "Combustibles alternativos en motores de combustión interna de cilindrada entre 1,200 y 2,000 centímetros cúbicos", que fue realizada durante el año 2012, mediante el patrocinio del Instituto de Investigación Científica de la Universidad de Lima.

* Correos electrónicos: jgoni@ulima.edu.pe, mrojas@ulima.edu.pe. 


\section{INTRODUCCIÓN}

\subsection{Biocombustibles}

Se denominan biocombustibles a los combustibles que se obtienen a partir de biomasa, mediante un proceso sostenible. Los llamados biocombustibles de primera generación suponen la existencia de otro tipo de biocombustibles, denominados biocombustibles de segunda generación, actualmente en desarrollo.

$\mathrm{Si}$ bien no existe una definición clara al respecto, se entiende que los biocombustibles de primera generación son aquellos que se producen a partir de materias primas convencionales, reducen emisiones de gases de efecto invernadero en relación con los combustibles fósiles, tienen presencia en el mercado, son muy importantes para el desarrollo de nuevas generaciones de biocombustibles y se producen sosteniblemente.

Para la obtención de biocombustibles se utilizan también insumos empleados para la alimentación humana, lo cual ha generado preocupación y críticas por parte de la población, debido a que esto puede generar el encarecimiento de los alimentos.

El ingreso en el mercado de biocombustibles de primera generación mezclados con combustibles de origen fósil, a pesar de su mayor precio, ha motivado su comercialización, lo cual ha permitido lograr una menor contaminación atmosférica, la cual también depende de la materia prima empleada para la fabricación del biocombustible y del tipo de producto obtenido.

Para la existencia de los biocombustibles de segunda generación ha sido necesario que primero existan los biocombustibles de primera generación; y se ha logrado ya la coexistencia de ambas generaciones. Un requisito obligatorio para la producción de cualquier tipo y generación de biocombustible es que este se produzca de una manera sostenible.

Entre los principales biocombustibles de primera generación que se pueden producir sosteniblemente están el biodiésel, el bioetanol y el biogás.

En la tabla 1 se muestra un referencial de clasificación tentativa y la evolución actual de los biocombustibles. 
Tabla 1

Clasificación de biocombustibles por recursos y procesos

\begin{tabular}{ll}
\hline Generación & \multicolumn{1}{c}{ Recursos y procesos } \\
\hline Primera & $\begin{array}{l}\text { Cultivos alimentarios para hacer combustibles: biodiésel de acei- } \\
\text { te vegetal (transesterificación) y bioetanol (fermentación de so- } \\
\text { luciones azucaradas). }\end{array}$ \\
\hline \multirow{2}{*}{ Segunda } & $\begin{array}{l}\text { Cultivos no alimentarios o en tierras de cultivo marginales no } \\
\text { aptas para cultivos alimentarios para hacer biocombustibles. Se } \\
\text { considera procesamiento de biomasa, lípidos marginales para } \\
\text { biodiésel y lignocelulósicos para alcohol. }\end{array}$ \\
\hline Tercera & $\begin{array}{l}\text { No se usan tierras arables y la biomasa se descompone para } \\
\text { obtener materia prima para hacer combustibles. Se considera el } \\
\text { procesamiento de microalgas para obtener biodiésel (liporrefine- } \\
\text { ría) y bioetanol (lignocelurefinería). }\end{array}$ \\
\hline \multirow{3}{*}{ Cuarta } & $\begin{array}{l}\text { No se usan tierras arables y la biomasa no se descompone para } \\
\text { hacer combustibles. Se considera el procesamiento de microal- } \\
\text { gas para obtener biodiésel por termoconversión (liporrefinería). }\end{array}$ \\
Está actualmente en desarrollo.
\end{tabular}

Elaboración propia.

1.2 Relación entre combustible, seguridad energética y servicio de motor

En la tabla 2 se muestra el referencial de seguridad energética y uso de combustibles en motores, como factores claves en el desarrollo industrial en el ámbito internacional y en el Perú.

Tabla 2

Relación entre combustible, seguridad energética y servicio de motor

\begin{tabular}{lll}
\hline Combustible & \multicolumn{1}{c}{ Seguridad energética } & \multicolumn{1}{c}{ Servicio de motor } \\
\hline Biodiésel & $\begin{array}{l}\text { El biodiésel se produce en el Pe- } \\
\text { rú, pero no cubre la demanda. }\end{array}$ & $\begin{array}{l}\text { Sellos y mangueras del motor } \\
\text { pueden ser afectados, pero mejo- } \\
\text { ra la lubricidad. }\end{array}$ \\
\hline $\begin{array}{l}\text { Gas natural } \\
\text { comprimido }\end{array}$ & $\begin{array}{l}\text { Se produce en el Perú y se cuen- } \\
\text { ta con reservas. Uso poblacional, } \\
\text { automotor y comercial. }\end{array}$ & $\begin{array}{l}\text { Los tanques de acero de alta resis- } \\
\text { tencia de los vehículos requieren } \\
\text { inspección y certificación. }\end{array}$ \\
\hline
\end{tabular}

(continúa) 
(continuación)

\begin{tabular}{|c|c|c|}
\hline Combustible & Seguridad energética & Servicio de motor \\
\hline $\begin{array}{l}\text { Petróleo } \\
\text { diésel n. } 2\end{array}$ & $\begin{array}{l}\text { El Perú importa el diésel } n .^{\circ} 2 \text { de } \\
\text { muy bajo contenido de azufre. }\end{array}$ & Convencional, normal. \\
\hline Electricidad & $\begin{array}{l}\text { Nuestro país se cuenta con plan- } \\
\text { tas termoeléctricas a gas natural, } \\
\text { biogás e hidroeléctricas. }\end{array}$ & $\begin{array}{l}\text { En vehículos con motores eléctri- } \\
\text { cos, se reduce el servicio de man- } \\
\text { tenimiento, pero tiene mayor peso. }\end{array}$ \\
\hline Bioetanol & $\begin{array}{l}\text { En el Perú se produce el bioeta- } \\
\text { nol pero no sin que se cubra la } \\
\text { demanda. Para obtener alcohol } \\
\text { carburante se desnaturaliza. }\end{array}$ & $\begin{array}{l}\text { Puede requerirse lubricantes es- } \\
\text { peciales. Servicio similar a los mo- } \\
\text { tores de ciclo Otto. }\end{array}$ \\
\hline Gasolina & $\begin{array}{l}\text { Se importa gasolina especial por } \\
\text { número de octano y bajo conteni- } \\
\text { do de azufre. }\end{array}$ & Convencional, normal. \\
\hline Hidrógeno & $\begin{array}{l}\text { Se produce en nuestro país solo } \\
\text { para uso industrial. }\end{array}$ & $\begin{array}{l}\text { Está en desarrollo para uso en cel- } \\
\text { das de combustible. }\end{array}$ \\
\hline $\begin{array}{l}\text { Gas natural } \\
\text { licuado }\end{array}$ & Se produce para exportación. & $\begin{array}{l}\text { Los tanques de acero de alta re- } \\
\text { sistencia requieren inspección y } \\
\text { certificación. }\end{array}$ \\
\hline $\begin{array}{l}\text { Gas licuado } \\
\text { de petróleo }\end{array}$ & $\begin{array}{l}\text { Se produce para uso poblacional, } \\
\text { automotor y comercial. }\end{array}$ & $\begin{array}{l}\text { Ha tenido uso automotor y compi- } \\
\text { te con el gas natural vehicular. }\end{array}$ \\
\hline Metanol & $\begin{array}{l}\text { Mínima producción, como sub- } \\
\text { producto. }\end{array}$ & $\begin{array}{l}\text { Se deben usar lubricantes espe- } \\
\text { ciales y compatibilidad, también } \\
\text { en autopartes. }\end{array}$ \\
\hline
\end{tabular}

Fuente: US-DOE-FDC Alternative Fuels Data Center, 2011.

Elaboración propia.

\subsection{Evolución de la generación de gases de efecto invernadero (GEI)}

Los gases de efecto invernadero se definen como gases integrantes de la atmósfera, de origen natural y antropogénico, que absorben y emiten radiación en determinadas longitudes de ondas del espectro de radiación infrarroja emitido por la superficie de la Tierra, la atmósfera, 
y las nubes. Esta propiedad causa el efecto invernadero. El vapor de agua $\left(\mathrm{H}_{2} \mathrm{O}\right)$, el dióxido de carbono $\left(\mathrm{CO}_{2}\right)$, el óxido nitroso $\left(\mathrm{NO}_{2}\right)$, el metano $\left(\mathrm{CH}_{4}\right)$ y el ozono $\left(\mathrm{O}_{3}\right)$ son los principales gases de efecto invernadero en la atmósfera terrestre.

En la tabla 3 se observa la evolución creciente de emisión de gases de efecto invernadero entre el 2005 y el 2008, luego desciende el 2009 con el inicio del uso de gasohol, DB2 y DB5, y desde este año aumenta en proporción al crecimiento del parque automotor entre los años 2010 y 2012.

Tabla 3

Evolución de gases de efecto invernadero en el Perú, en el periodo 2005-2012 (kt $\mathrm{CO}_{2}$ eq.)

\begin{tabular}{ccccccccc}
\hline Año & $\mathbf{2 0 0 5}$ & $\mathbf{2 0 0 6}$ & $\mathbf{2 0 0 7}$ & $\mathbf{2 0 0 8}$ & $\mathbf{2 0 0 9}$ & $\mathbf{2 0 1 0}$ & $\mathbf{2 0 1 1}$ & $\mathbf{2 0 1 2}$ \\
\hline \multirow{2}{*}{ Magnitud } & 150,324 & 160,061 & 163,925 & 167,373 & 143,075 & 147,978 & 151,930 & 155,883 \\
\hline
\end{tabular}

Fuente: Minam, Sinia, 2013.

Elaboración propia.

\subsection{Objetivo y justificación}

El objetivo general del trabajo de investigación fue la evaluación comparativa del uso de mezclas de combustibles convencionales y combustibles alternativos en motores de combustión interna, respecto de sus parámetros de funcionamiento.

Para tal fin se prepararon las mezclas de gasolina-alcohol carburante y de petróleo diésel n. ${ }^{\circ}$ 2-biodiésel, para realizar en un banco de pruebas las mediciones de régimen, torque, potencia, consumo de combustible y determinación de la eficiencia del motor.

La evaluación ha considerado las funciones (relaciones): consumotorque, consumo-potencia, eficiencia-torque, eficiencia-potencia, eficiencia-consumo y eficiencia-régimen. Se consideraron como línea base los libros de Rojas et al. (2006) y Goñi (2009).

La investigación se sustenta en el ensayo de mezclas de combustibles derivados del petróleo con una mayor cantidad de biocombustibles, para reducir la emisión de gases de efecto invernadero causantes del cambio climático en el planeta (véase la tabla 3). 
Como hipótesis de trabajo se consideró que las mezclas de gasolina y petróleo diésel n. ${ }^{\circ} 2$ con alcohol carburante y biodiésel, respectivamente, mejoran la combustión en un motor, debido a la mayor presencia de oxígeno en la mezcla.

\subsection{Planteamiento general del trabajo de investigación}

En la figura 1 se muestra el diagrama conceptual del planteamiento general del trabajo de investigación; este comprende el marco referencial y conceptual, el trabajo experimental, el análisis y discusión de los resultados; todos los cuales conducen a las conclusiones.

Figura 1

Diagrama del planteamiento de la investigación

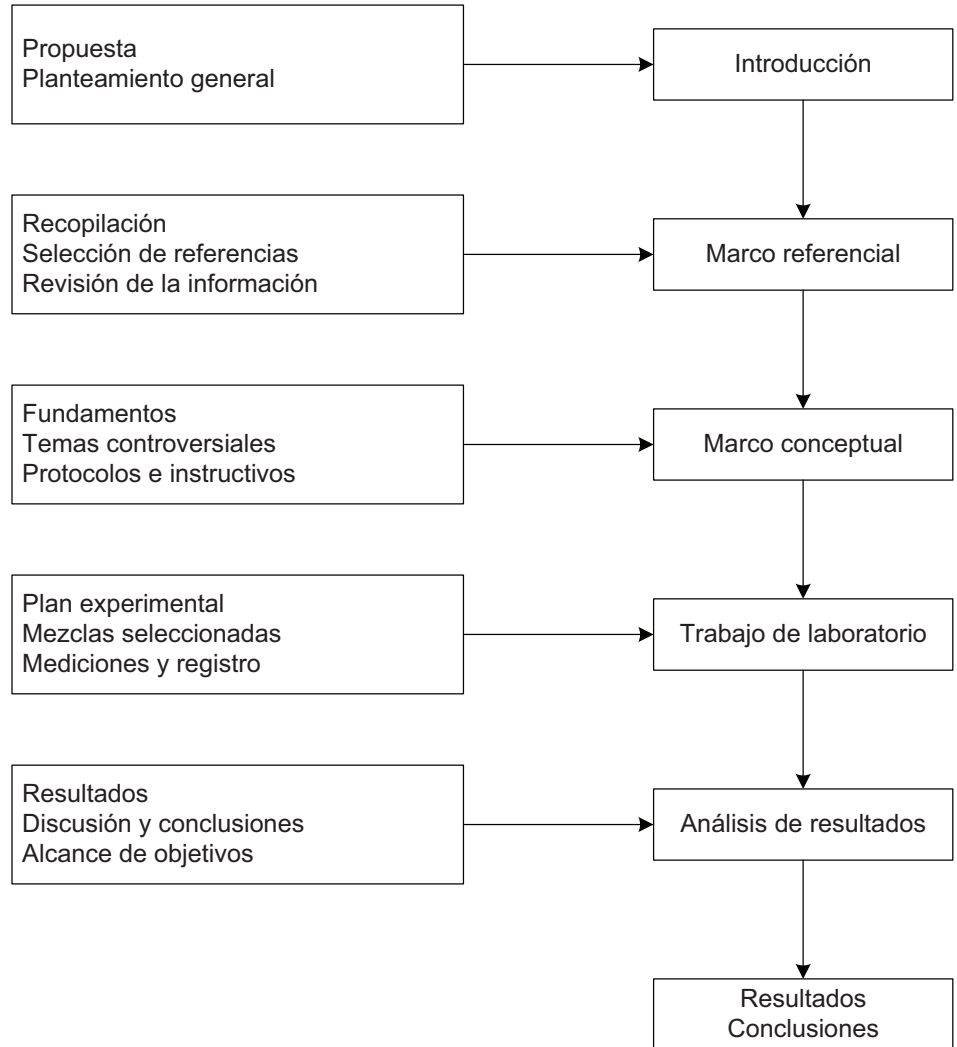

Elaboración propia. 
2. MEDICIÓN EXPERIMENTAL DE LA POTENCIA DE UN MOTOR Y SUS PARÁMETROS TÉCNICOS DE FUNCIONAMIENTO, MEDIANTE EL USO DE COMBUSTIBLES SELECCIONADOS

a) Se planteó hacer la medición de datos experimentales en un banco de pruebas dinamométrico para motores de combustión interna (véase la figura 2).

Figura 2

Diagrama simplificado del sistema de ensayo de motores de combustión interna

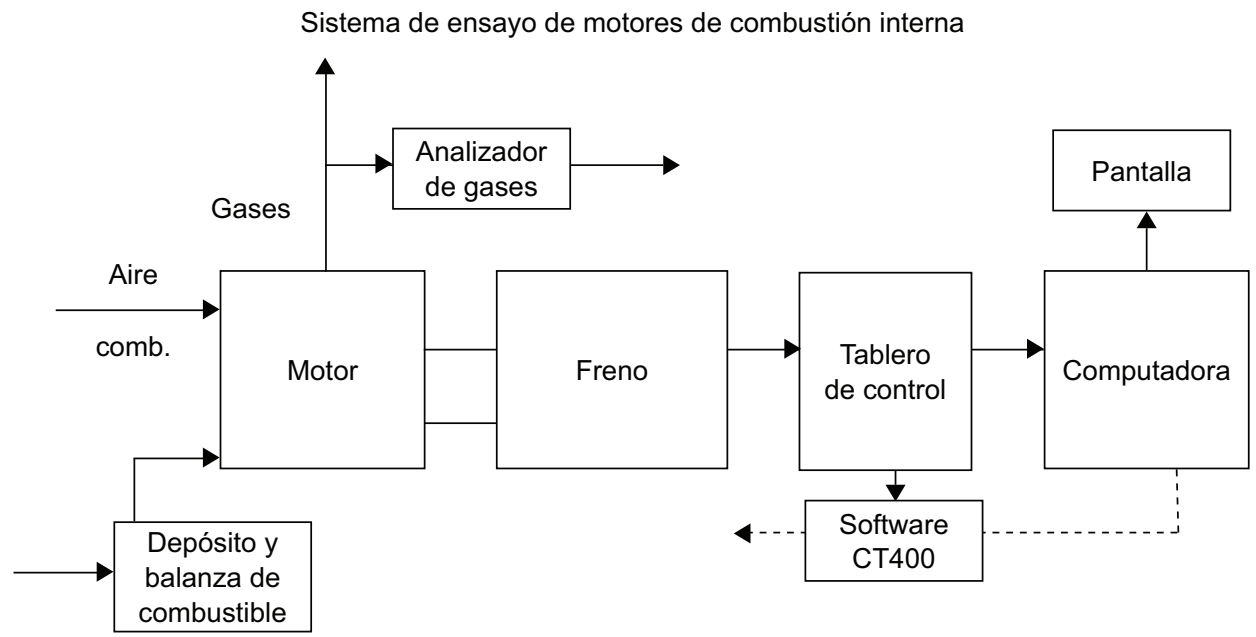

Fuente: GUNT (2007).

Elaboración propia.

b) Se planteó preparar las mezclas de combustibles que se van a ensayar en el motor de ciclo Otto (Mezclas G95EZ) y para el motor de ciclo diésel (mezclas DBX). A través del apoyo de Osinergmin, se estimaron los contenidos de alcohol carburante y biodiésel, respectivamente (véanse las tablas 4 y 5 ). 
Tabla 4

Relación de mezclas G95EZ ensayadas

\begin{tabular}{cccc}
\hline \multicolumn{4}{c}{ Contenido de alcohol carburante (alcohol desnaturalizado) } \\
\hline \multirow{2}{*}{$\begin{array}{c}\text { Mezcla nominal } \\
\text { (G95EZ) }\end{array}$} & \multicolumn{3}{c}{ Alcohol carburante (\% volumen y masa medidos) } \\
\cline { 2 - 4 } & \% Vol. Nomin.-Medido-Difer. & $\%$ Vol. & $\%$ Masa \\
\hline G95E7.8 & $7.8-7.8-\Delta 1.1$ & 8.9 & 9.4 \\
G95E10 & $10.0-10.3-\Delta 1.4$ & 11.7 & 12.3 \\
G95E12 & $12.0-12.8-\Delta 1.5$ & 14.3 & 15.0 \\
\hline
\end{tabular}

Elaboración propia.

Tabla 5

Relación de mezclas (DBX) ensayadas

\begin{tabular}{ccccc}
\hline \multicolumn{4}{c}{ Contenido de biodiésel (ester metílico de ácido graso-FAME*) } \\
\hline \multirow{2}{*}{$\begin{array}{c}\text { Mezcla nominal } \\
\text { (DBX) }\end{array}$} & \multicolumn{4}{c}{ Biodiésel (\% Volumen medido) } \\
\cline { 2 - 5 } & Registro 1 & Registro 2 & Registro 3 & Promedio \\
\hline DB5 & 5.0 & 4.9 & 4.8 & 4.9 \\
DB10 & 10.7 & 10.7 & 10.6 & 10.7 \\
DB12 & 12.9 & 12.9 & 12.8 & 12.9 \\
\hline
\end{tabular}

* Fatty Acid Methyl Ester.

Elaboración propia.

c) Se planteó determinar régimen, torque, potencia, consumo de combustible y eficiencia para las pruebas de la mezcla G95EZ en el motor de ciclo Otto, marca Ford, de 1,400 centímetros cúbicos; y las mezclas DBX en el motor de ciclo Diésel, marca Volkswagen, de 1,800 centímetros cúbicos (véase la tabla 6). 
Tabla 6

Plan de ensayos de las mezclas G95EZ (motor de ciclo Otto)

y DBX (motor de ciclo Diésel)

\begin{tabular}{|c|c|c|}
\hline Plan de ensayos & $\begin{array}{l}\text { bustibles } \\
\text { do por ch }\end{array}$ & I motor de \\
\hline & yar (G95E & \\
\hline G95E7.8 & G95E10 & G95E12 \\
\hline Relación de pará & dos para & ciclo Otto \\
\hline & $2,050 \mathrm{rpm}$ & \\
\hline Consumo $(\mathrm{kg} / \mathrm{h})$ vers & & \\
\hline Consumo $(\mathrm{kg} / \mathrm{h})$ vers & & \\
\hline Eficiencia (\%) versu & & \\
\hline Eficiencia (\%) versu & & \\
\hline Eficiencia (\%) versu & ustible (ks & \\
\hline & Variable & \\
\hline
\end{tabular}

Elaboración propia.

\begin{tabular}{|c|c|c|}
\hline \multicolumn{3}{|c|}{$\begin{array}{c}\text { Plan de ensayos de mezclas de combustibles DBX en el motor } \\
\text { de ciclo Diésel (encendido por compresión) }\end{array}$} \\
\hline \multicolumn{3}{|c|}{ Mezclas por ensayar (DBX) } \\
\hline DB5 & DB10 & DB12 \\
\hline \multicolumn{3}{|c|}{ Relación de parámetros seleccionados para el motor de ciclo Diése } \\
\hline \multicolumn{3}{|c|}{ Régimen $(n)=1,500 \mathrm{rpm}$} \\
\hline \multicolumn{3}{|c|}{ Consumo $(\mathrm{kg} / \mathrm{h})$ versus torque $(\mathrm{Nm})$} \\
\hline \multicolumn{3}{|c|}{ Consumo (kg/h) versus potencia (kW) } \\
\hline \multicolumn{3}{|c|}{ Eficiencia $(\%)$ versus torque $(\mathrm{Nm})$} \\
\hline \multicolumn{3}{|c|}{ Eficiencia $(\%)$ versus potencia $(\mathrm{kW})$} \\
\hline \multicolumn{3}{|c|}{ Eficiencia $(\%)$ versus consumo de combustible $(\mathrm{kg} / \mathrm{h})$} \\
\hline \multicolumn{3}{|c|}{ Régimen $(\mathrm{n})=$ Variable } \\
\hline Eficiencia (\%) ver & carga ( & \\
\hline
\end{tabular}

Elaboración propia.

d) Se planteó el uso del siguiente formato para el registro de datos (véase la tabla 7). 


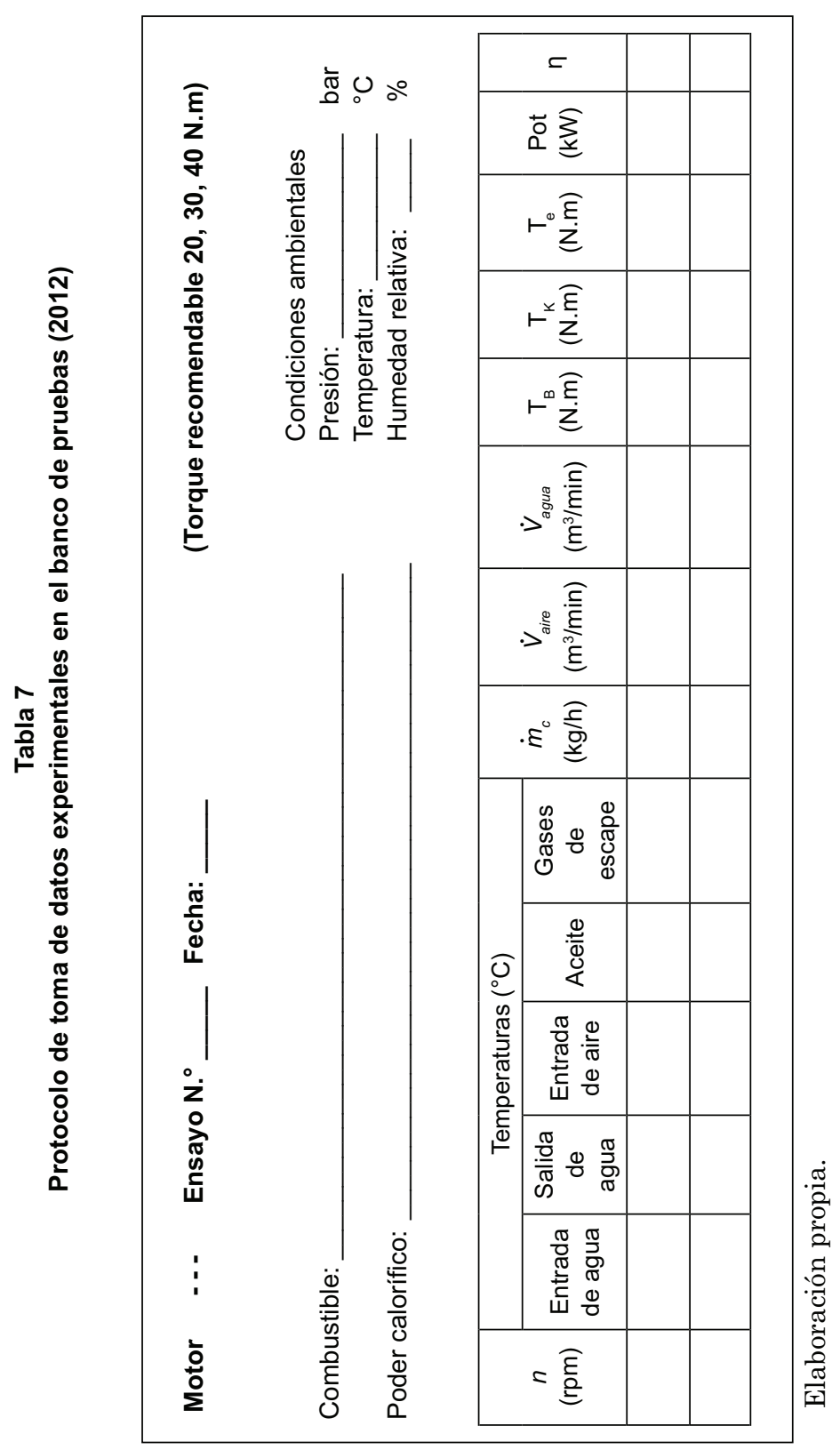




\section{RESULTADOS EXPERIMENTALES CORRELACIONADOS Y DISCUSIÓN}

\subsection{Resultados y discusión de ensayos de mezclas G95Z en el motor de ciclo Otto}

En la tabla 8 se presentan los resultados y la discusión de las correlaciones de los parámetros indicados según los datos experimentales obtenidos para las mezclas G95Z, los cuales han sido obtenidos con el banco de pruebas para el motor de ciclo Otto.

Tabla 8

Discusión de resultados para mezclas G95Z en motor de ciclo Otto

\begin{tabular}{cl}
\hline $\begin{array}{c}\text { Relación de } \\
\text { parámetros } \\
\text { del motor }\end{array}$ & \multicolumn{1}{c}{ Motor de ciclo Otto } \\
\cline { 2 - 3 } Consumo-torque & $\begin{array}{l}\text { El consumo de combustible varía y aumenta con el torque en } \\
\text { la misma proporción para los diferentes porcentajes de alcohol } \\
\text { carburante sin una diferencia significativa. }\end{array}$ \\
\hline Consumo-potencia & $\begin{array}{l}\text { El consumo de combustible para una determinada potencia } \\
\text { entregada por el motor no se ve afectado significativamente con } \\
\text { el incremento de alcohol carburante en la mezcla. }\end{array}$ \\
\hline Eficiencia-torque & $\begin{array}{l}\text { El efecto de la eficiencia con respecto al torque sigue una tendencia } \\
\text { similar que la relación consumo-torque con el incremento de } \\
\text { alcohol carburante en la mezcla. }\end{array}$ \\
\hline Eficiencia-potencia & $\begin{array}{l}\text { La eficiencia con respecto a la potencia sigue una correlación } \\
\text { similar que la tendencia consumo-potencia ante el incremento del } \\
\text { alcohol carburante en la mezcla. }\end{array}$ \\
\hline Eficiencia-consumo & $\begin{array}{l}\text { No se observa diferencia significativa en la curva eficiencia- } \\
\text { consumo al variar el porcentaje de mezcla gasolina-alcohol } \\
\text { carburante. }\end{array}$ \\
\hline Eficiencia-régimen & $\begin{array}{l}\text { A pesar de que esta relación se obtuvo sin carga del motor (solo } \\
\text { las perdidas por el freno dinamométrico) la pequeña eficiencia se } \\
\text { incrementó significativamente con el régimen del motor para cada } \\
\text { una de las mezclas. En este caso la eficiencia mejoró ligeramente } \\
\text { con el incremento del contenido de alcohol carburante en la } \\
\text { mezcla. }\end{array}$ \\
\hline
\end{tabular}

Elaboración propia. 


\subsection{Resultados y discusión de ensayos de mezclas DBX en el motor de ciclo Diésel}

En la tabla 9 se presentan los resultados y discusión de las correlaciones de los parámetros indicados, según los datos experimentales obtenidos para las mezclas DBX, que han sido determinados en el banco de pruebas para el motor de ciclo Diésel.

Tabla 9

Discusión de resultados para mezclas DBX en motor de ciclo Diésel

\begin{tabular}{cccc}
\hline $\begin{array}{c}\text { Relación de } \\
\text { parámetros } \\
\text { del motor }\end{array}$ & DB5 & Motor de ciclo Diésel & DB10 \\
\cline { 2 - 4 }
\end{tabular}

Consumo-torque $\quad \begin{aligned} & \text { tiene una tendencia a la baja ante el incremento en porcentaje } \\ & \text { de biodiésel para la mezcla. Este efecto se observa a diferentes } \\ & \text { torques. }\end{aligned}$

\begin{tabular}{ll}
\hline Consumo-potencia & $\begin{array}{l}\text { El consumo de combustible para una potencia entregada va } \\
\text { disminuyendo con el aumento de la proporción del biodiésel en } \\
\text { la mezcla. Esta disminución del consumo se registra a diferentes } \\
\text { potencias. }\end{array}$ \\
\hline Eficiencia-torque & $\begin{array}{l}\text { El efecto de la eficiencia con respecto al torque sigue una } \\
\text { tendencia ligeramente descendente ante el incremento del } \\
\text { biodiésel en la mezcla. }\end{array}$ \\
\hline Eficiencia-potencia & $\begin{array}{l}\text { La eficiencia con respecto a la potencia del motor sigue una } \\
\text { tendencia ligeramente ascendente con el incremento del biodiésel } \\
\text { en la mezcla. }\end{array}$ \\
\hline Eficiencia-consumo & $\begin{array}{l}\text { De las pruebas obtenidas, a bajo consumo de combustible, la } \\
\text { eficiencia aumenta ligeramente con el incremento del contenido } \\
\text { de biodiésel. A medida que se va incrementando el consumo } \\
\text { de combustible, esta tendencia empieza a cambiar: se hace } \\
\text { constante e incluso ligeramente descendente. }\end{array}$ \\
\hline Eficiencia-régimen & $\begin{array}{l}\text { Esta relación se obtiene para prueba sin carga del motor (solo las } \\
\text { perdidas por el freno dinamométrico) y la pequeña eficiencia se } \\
\text { mantiene aproximadamente en el mismo orden de magnitud para } \\
\text { las diferentes mezclas petróleo diésel-biodiésel ensayadas. }\end{array}$ \\
\hline
\end{tabular}

Elaboración propia. 


\subsection{Comparación con trabajos similares}

En el ámbito nacional no se conocen referencias de pruebas con mezclas de gasolina con bajo contenido de azufre y alcohol carburante ni con mezclas de petróleo diésel de bajo contenido de azufre y biodiésel, debido a que las refinerías locales no las producen. Al respecto, cabe citar resultados de pruebas de campo hechas en Colombia, con motores de ciclo Diésel, empleando mezclas de petróleo diésel y biodiésel en buses y camiones.

En Colombia se han desarro-llado pruebas en buses y camiones, empleando biodiésel de primera generación. En la tabla 10 se muestran algunos resultados de estas pruebas, lo que refuerza la posibilidad de hacerla en el futuro con mayor contenido de biodiésel.

Tabla 10

Resumen de las pruebas realizadas con mezclas DBZ

\begin{tabular}{lll}
\hline \multicolumn{1}{c}{ Características } & Mezclas probadas & \multicolumn{1}{c}{ Conclusión } \\
\hline $\begin{array}{l}\text { Pruebas de larga duración } \\
\text { utilizando doce buses arti- } \\
\text { culados del operador 5199 } \\
\text { del sistema Transmilenio en } \\
\text { Bogotá }\end{array}$ & DB20,DB30,DB50 & $\begin{array}{l}\text { Este combustible ecológico se } \\
\text { puede incorporar a vehículos a } \\
\text { diésel en mezclas de } 5 \%, 10 \%, \\
20 \%, 30 \% \text { y hasta } 50 \%, \text { sin pro- } \\
\text { blemas en los motores y en la } \\
\text { inyección. }\end{array}$ \\
\hline $\begin{array}{l}\text { Pruebas en nueve camiones } \\
\text { que recorrieron las carrete- } \\
\text { ras de Colombia }\end{array}$ & DB5, DB10, DB20 & $\begin{array}{l}\text { Tuvo un buen desempeño, sin } \\
\text { incremento en el consumo de } \\
\text { combustible y con niveles nor- } \\
\text { males de desgaste en el motor. }\end{array}$ \\
\hline $\begin{array}{l}\text { Prueba con equipos de ope- } \\
\text { ración minera }\end{array}$ & DB5 y DB10 & $\begin{array}{l}\text { Tuvo un buen desempeño co- } \\
\text { mo combustible. }\end{array}$ \\
\hline
\end{tabular}

Fuente: Ecopetrol-Cenipalma-Fedepalm (2012). 


\subsection{Observaciones}

a) Comparativa de propiedades de los componentes de las mezclas de combustibles ensayadas. Al observar las cifras de la tabla 11 de propiedades de los componentes de las mezclas, se puede aseverar lo siguiente:

- El poder calorífico inferior (PCI) de una mezcla diésel-biodiésel y la de una mezcla gasolina-bioetanol desnaturalizado tiende a disminuir, según el porcentaje del respectivo biocombustible.

- La densidad de una mezcla diésel-biodiésel y de una mezcla gasolina-etanol tiende a elevarse, según el porcentaje del respectivo biocombustible.

Tabla 11

Algunas propiedades de los componentes de las mezclas de combustibles ensayadas

\begin{tabular}{lcccc}
\hline Propiedad & $\begin{array}{c}\text { Diésel bajo } \\
\text { azufre }\end{array}$ & Biodiésel & $\begin{array}{c}\text { Gasolina } \\
\text { bajo azufre }\end{array}$ & Bioetanol \\
\hline $\mathrm{PCl}(\mathrm{MJ} / \mathrm{kg})$ & 42.61 & 37.53 & 42.36 & 26.95 \\
Densidad (kg/L) & 0.8470 & 0.8880 & 0.7477 & 0.7894 \\
$\mathrm{DEVI}(\mathrm{MJ} / \mathrm{L})$ & 36.09 & 33.33 & 31.67 & 21.28 \\
Número de cetano* & $40-45^{*}$ & $48-65^{*}$ & ---- & ---- \\
Número de octano** & ---- & ---- & $84-93^{* *}$ & $110^{* *}$ \\
\hline
\end{tabular}

Fuente: US-DOE-FDC Alternative Fuels Data Center (2011).

Elaboración propia.

- La densidad energética volumétrica inferior (DEVI) de una mezcla diésel-biodiésel y de una mezcla gasolina-bioetanol desnaturalizado tiende a disminuir, según el porcentaje del respectivo biocombustible.

- El número de cetano de una mezcla diesel-biodiesel y el número de octano de una mezcla gasolina-etanol tienden a aumentar, según el porcentaje del respectivo biocombustible.

b) El primer trabajo de investigación de mezclas combustibles fósilesbiocombustibles, desarrollado en el Banco de Motores del Laborato- 
rio de Máquinas e Instrumentos de la Universidad de Lima se ha cumplido en una fase preliminar, bajo las siguientes condiciones:

La concentración del biocombustible en las mezclas ensayadas tiene carácter nominal. Se ha verificado el contenido del biocombustible con equipos de medición de laboratorio, y se ha observado que el combustible comercial de una refinería tiene diferente concentración de biocombustible al valor nominal.

c) Se tienen referencias de trabajos experimentales con otras mezclas de combustibles-biocombustibles con mayor concentración de biocombustible, pero con combustibles fósiles con alto contenido de azufre. Las mezclas ensayadas son combustibles fósiles con muy bajo contenido de azufre y menor concentración de biocombustible.

d) Se espera que a mayor concentración se obtengan mejores resultados con relación a los valores de los parámetros del motor, pero podría presentarse deterioro en los componentes de este.

Para una siguiente investigación, se recomienda incrementar la concentración del biocombustible, medir la composición de los gases de combustión, determinar el poder calorífico de las mezclas con ensayos de laboratorio y normalizar los procedimientos.

\section{CONCLUSIONES DEL TRABANO EXPERIMENTAL CON MEZCLAS DE COMBUSTIBLES EN MOTORES DE CICLO OTTO (G95EZ) Y DE CICLO DIÉSEL (DBX)}

El régimen promedio de trabajo de los motores a gasolina y con mezclas G95EZ es aproximadamente 2,000 rpm para la industria automotriz, donde el régimen mínimo parte de 800 rpm y llega hasta un máximo promedio de 6,000 rpm para los motores actuales.

En un servicio normal, los autos con motor de ciclo Otto y de 1,400 centímetros cúbicos, desarrollan 2,000 rpm a un torque promedio de 40 $\mathrm{Nm}$, que representa aproximadamente el $42 \%$ de su carga máxima a dichas revoluciones.

Con el motor frío y hasta $\operatorname{los} 60^{\circ} \mathrm{C}$ de temperatura de agua de refrigeración, el motor a gasolina consume el doble de combustible en $\mathrm{kg} / \mathrm{h}$ para su calentamiento previo y llegar a su temperatura de trabajo. Aproximadamente a $80{ }^{\circ} \mathrm{C}$ de temperatura del agua, el consumo de combustible llega a su nivel de diseño. En los motores de ciclo Diésel, el efecto del consumo es de similares características. 
El régimen de trabajo de los motores de ciclo Diesel para la industria automotriz puede considerarse en alrededor de 1,500 rpm, con un giro de 600 rpm inicial y un máximo promedio de 3,600 rpm.

Los vehículos con motor de ciclo Diesel y tamaño de motor 1,800 centímetros cúbicos, desarrollan 1,500 rpm y una carga de $40 \mathrm{Nm}$ en servicio normal, lo cual representa el $35 \%$ de su carga máxima a dichas revoluciones.

La eficiencia de los motores a gasolina y gasohol puede llegar a $32 \%$, lo que representa una elevada energía, pérdida de calor o desaprovechamiento elevado de la energía entregada por el combustible. Esta tendencia en la eficiencia se mantuvo en las diferentes mezclas de combustible y biocombustible ensayados.

Para las mezclas de diésel-biodiésel la eficiencia llegó a 37 \%, que es un valor bajo de aprovechamiento de energía, sin embargo, es superior a los motores de ciclo Otto. Se concluye que los motores de encendido por compresión son más eficientes que los motores de encendido por chispa.

La eficiencia de los motores de combustión interna no es constante, y aumenta con el incremento de la carga o torque, hasta llegar a un valor máximo y luego la tendencia a descender significativamente.

Se observa que el incremento del consumo de combustible es mayor en los motores de ciclo Otto que en los motores de ciclo Diésel ante el aumento de carga o par motor, y conservando las rpm constantes. El coeficiente de exceso de aire o valor lambda en los motores de ciclo Otto es menor que la unidad, lo que hace una mezcla rica en la combustión y un mayor consumo.

Las emisiones contaminantes en los motores de ciclo Otto que funcionan con mezcla de alcohol carburante son menores que con gasolina pura. La molécula de los alcoholes contiene oxígeno y esto favorece la producción de vapor de agua en los gases de escape.

Como la relación estequiométrica de combustión del alcohol carburante es menor (9.4 kg aire/kg de alcohol), la mezcla G95EZ requerirá de menor cantidad de aire para su combustión completa. El combustible fósil tiene una relación estequiométrica de $14.7 \mathrm{~kg}$ aire/kg de combustible; es decir, para igual consumo de combustible, el alcohol carburante requiere un volumen de cilindrada menor en el motor. 
El alcohol carburante tiene un número de octano más elevado que las gasolinas, lo que incrementa su poder antidetonante. Este factor permite mejorar y elevar la relación de compresión de un motor que aumentan su potencia y eficiencia significativamente.

El poder calorífico del alcohol carburante es menor que el de las gasolinas, lo que representa una menor potencia efectiva final. Este parámetro puede ser compensado con el incremento en la inyección de combustible al motor, que requiere de menor aire estequiométrico, o se puede incrementar la relación de compresión del motor para mejorar su eficiencia.

Los diferentes números de octano de las mezclas con alcohol carburante no representan una limitación técnica en los motores, pues el adelanto de chispa según el número de octano puede ser regulado con la unidad de control del motor.

Se están realizando proyecciones para experimentar con un porcentaje de hidrógeno/oxígeno a inyectar en la mezcla aire-gasolina. La generación de hidrógeno se da con una celda electrolítica, que recibe carga eléctrica por medio del alternador del motor.

Finalmente, se concluye que al incrementar en las mezclas actuales G95E7.8 y DB5 el contenido de biocombustible a 10 y $12 \%$ en volumen, las nuevas mezclas ensayadas presentaron solo un leve efecto en los valores de los parámetros del motor.

\section{CONCLUSIONES RESPECTO AL EXAMEN GRÁFICO DE FUNCIONES DE TENDENCIA DE LOS RESULTADOS DE LAS MEZCLAS G95E12 Y DB12 PROBADAS EN EL LABORATORIO}

En este inciso, se muestran como ejemplo de todos los ensayos, los resultados de las pruebas realizadas con las mezclas de biocombustibles gasolina-alcohol carburante (G95E12) y petróleo diésel-biodiésel (DB12). El banco de pruebas para motores de combustión interna con un freno de corrientes parásitas acoplado tiene la opción de montar un motor de ciclo Diésel o uno de ciclo Otto, según sea el caso.

Cada prueba ha comprendido aproximadamente 16 registros o más, para obtener la correlación de cuatro puntos promedios para la variable independiente. En algunos casos fueron cinco puntos. 
Se aplicó una regresión polinómica; se logró un coeficiente de correlación para las mezclas G95E12 de 0.98 o mayor, y para las mezclas DB12 de 0.97 o mayor.

\subsection{Curvas de mezclas de G95 E12}

Se presentan las curvas de los ensayos realizados con las mezclas de combustible G95E12, en proporción gasolina 95 octanos 88.0 \% y alcohol carburante $12.0 \%$ en volumen. Este combustible no se encuentra en el mercado nacional.

La primera curva muestra el consumo de combustible en $\mathrm{kg} / \mathrm{h}$ en función del torque del motor. El consumo de combustible tiende a incrementarse con el aumento del torque exigido o carga por vencer, en $\mathrm{Nm}$.

Figura 3

Consumo versus torque del combustible G95 E12

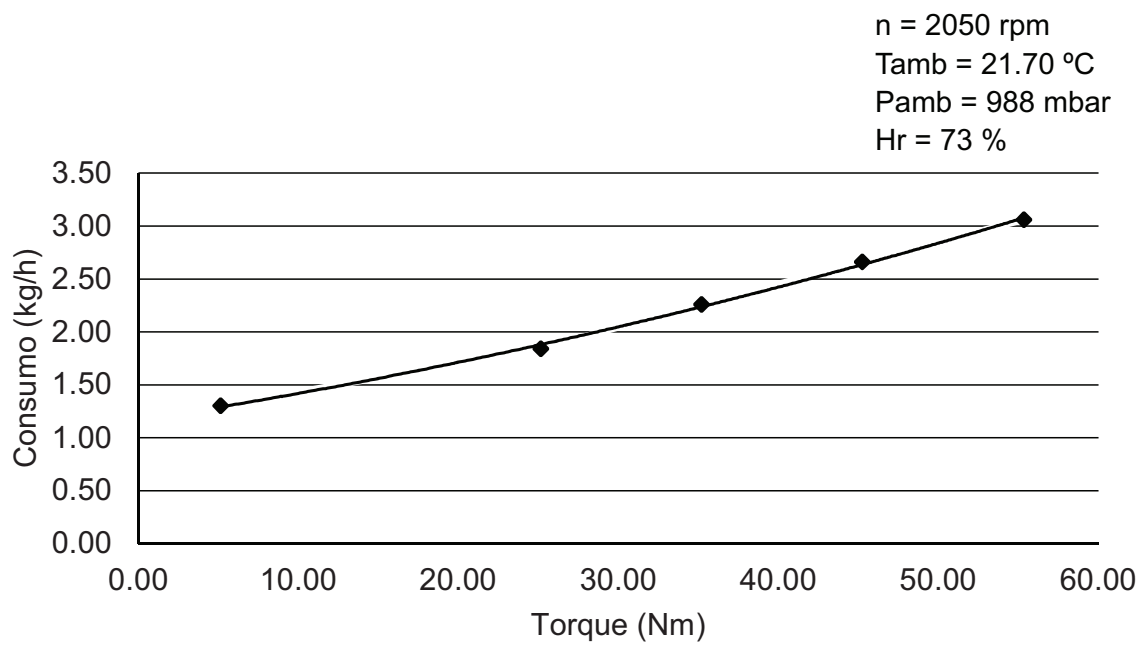

Elaboración propia. 
La segunda curva muestra el consumo de combustible en $\mathrm{kg} / \mathrm{h}$ en función de la potencia efectiva entregada por el eje cigüeñal, en $\mathrm{kW}$. La tendencia del consumo de combustible es de un incremento levemente parabólico.

Figura 4

Consumo versus potencia G95 E12

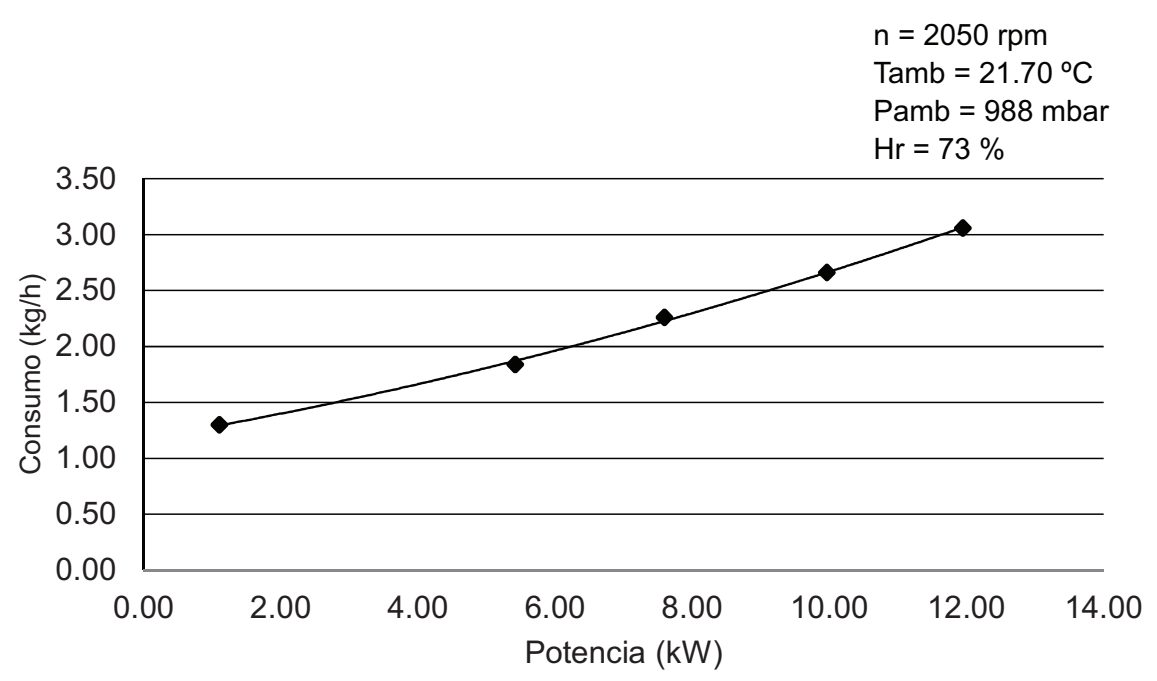

Elaboración propia. 
La tercera curva muestra la eficiencia efectiva del motor en función del torque, con una tendencia polinómica hacia el $32 \%$ de eficiencia constante. Cuando la carga es cero, la eficiencia es cero, pues no se transmite potencia ni torque; pero el motor consume combustible para su funcionamiento.

Figura 5

Eficiencia versus torque G95 E12

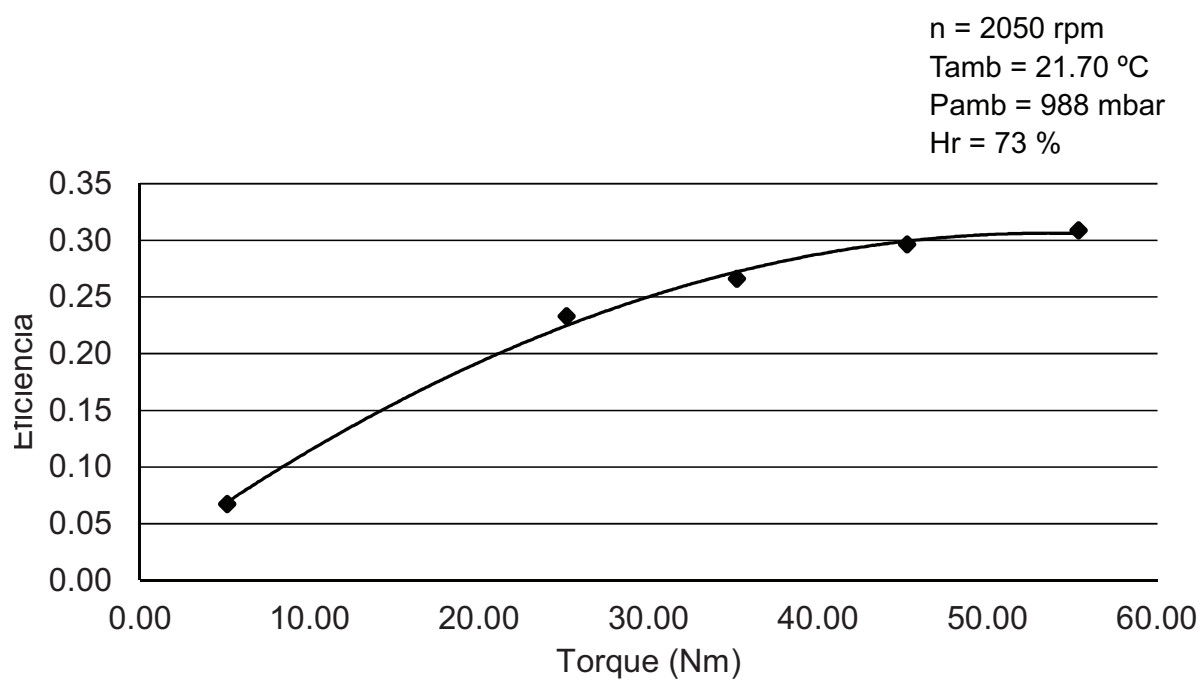

Elaboración propia. 
En la cuarta curva se observa que la eficiencia sigue una tendencia polinómica cercana a las mezclas G95 E7.8 y G95 E10.

Figura 6

Eficiencia versus potencia G95 E12

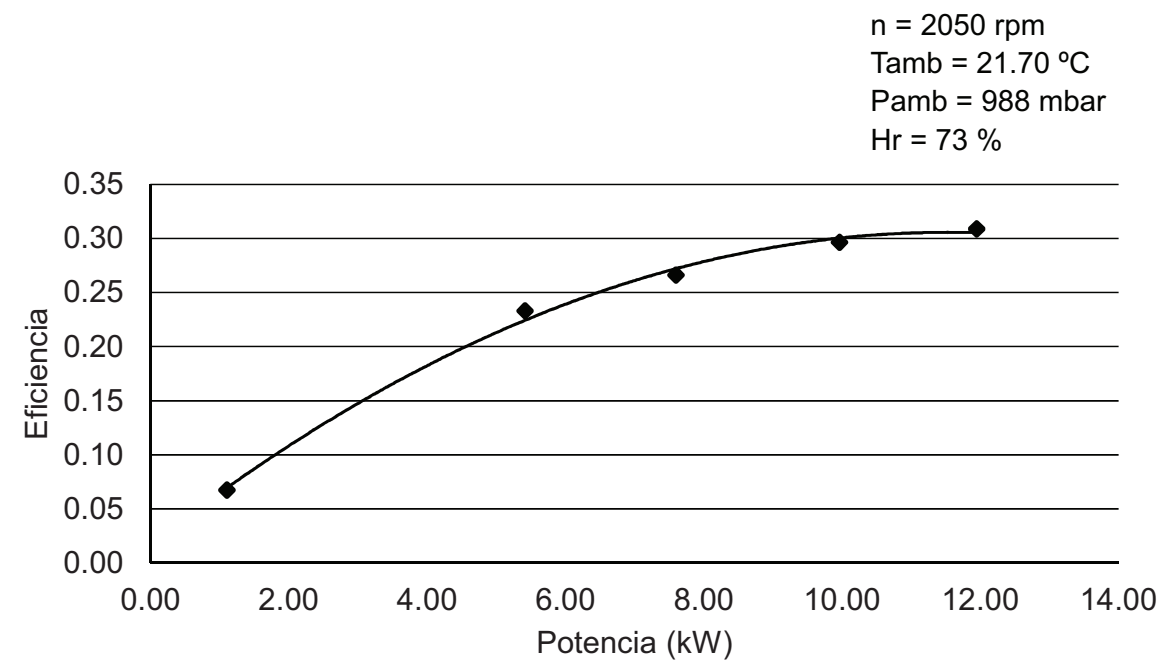

Elaboración propia. 
La quinta curva muestra la eficiencia versus el consumo de combustible, marcando una tendencia polinómica con pico máximo de eficiencia hacia un valor constante del $32 \%$. Sin embargo, el consumo de combustible se eleva fuertemente.

Figura 7

Eficiencia versus consumo G95 E12

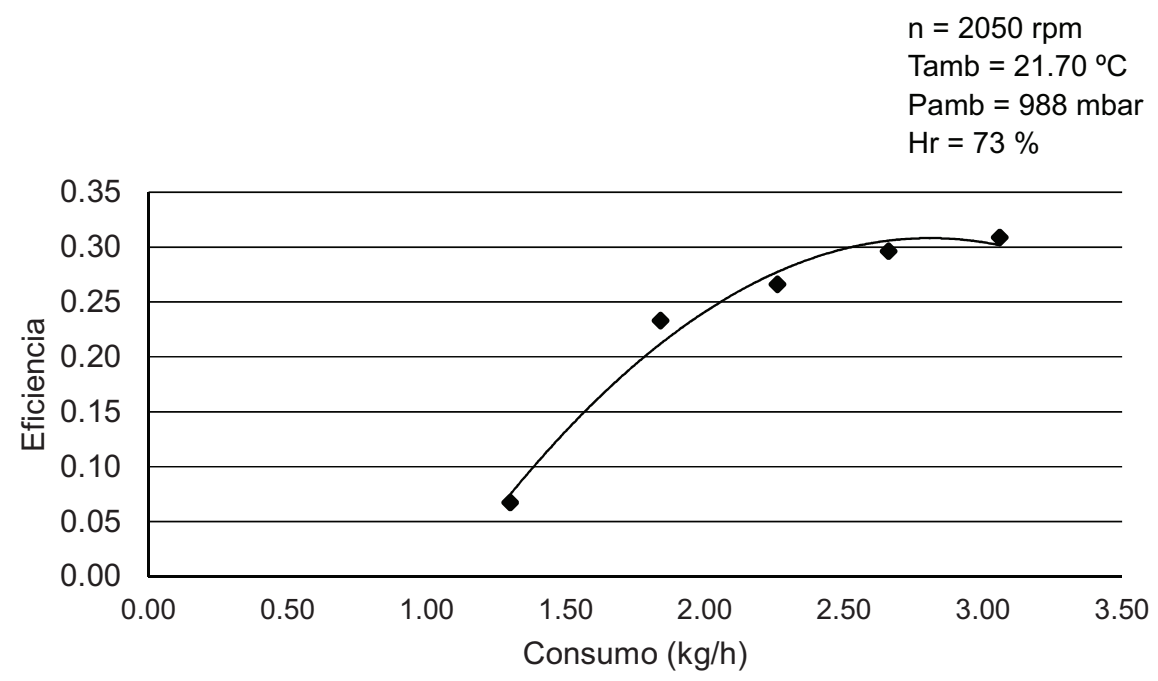

Elaboración propia. 
La sexta curva muestra la eficiencia versus el régimen en rpm, donde se deben vencer solo las pérdidas que originan la turbulencia del aire del giro del freno dinamométrico.

Figura 8

Eficiencia versus régimen G95 E12

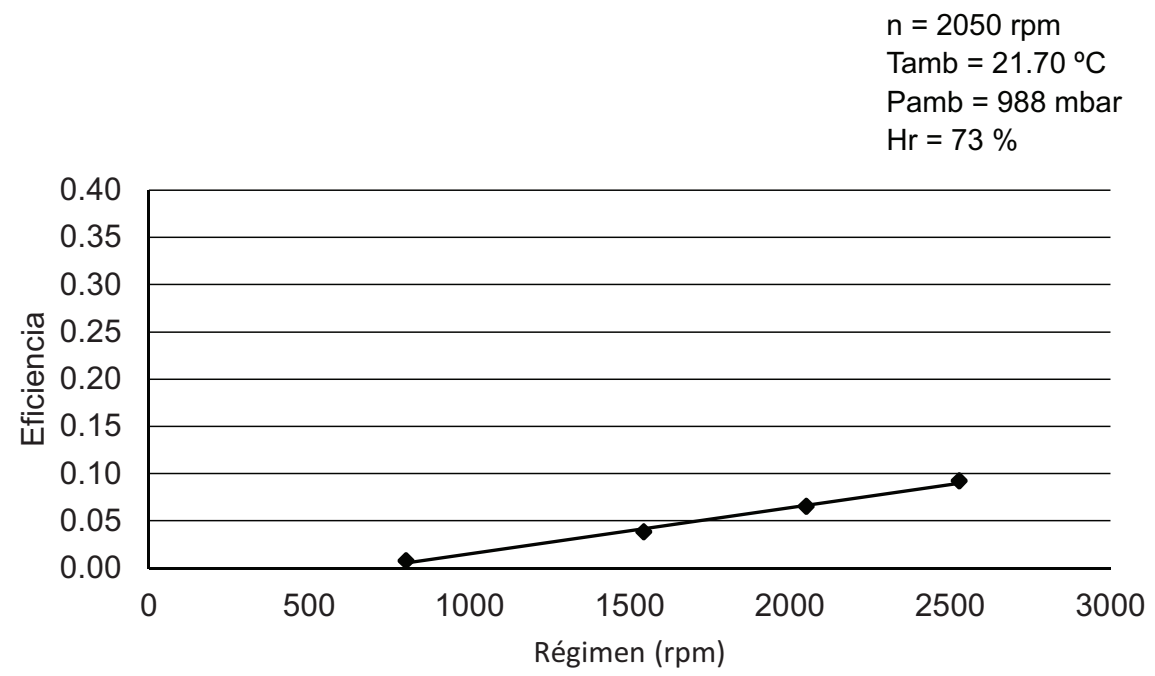

Elaboración propia. 


\subsection{Curvas de mezclas de DB12}

Se presentan las curvas de los ensayos realizados con las mezclas de combustible DB12, en proporción diésel 88,0 \% y biodiésel 12,0 \% en volumen.

La primera curva muestra el consumo de combustible en $\mathrm{kg} / \mathrm{h}$ en función del torque del motor. El consumo de combustible tiende a incrementarse con el aumento de torque exigido o carga por vencer, en $\mathrm{Nm}$.

Figura 9

Consumo versus torque DB12

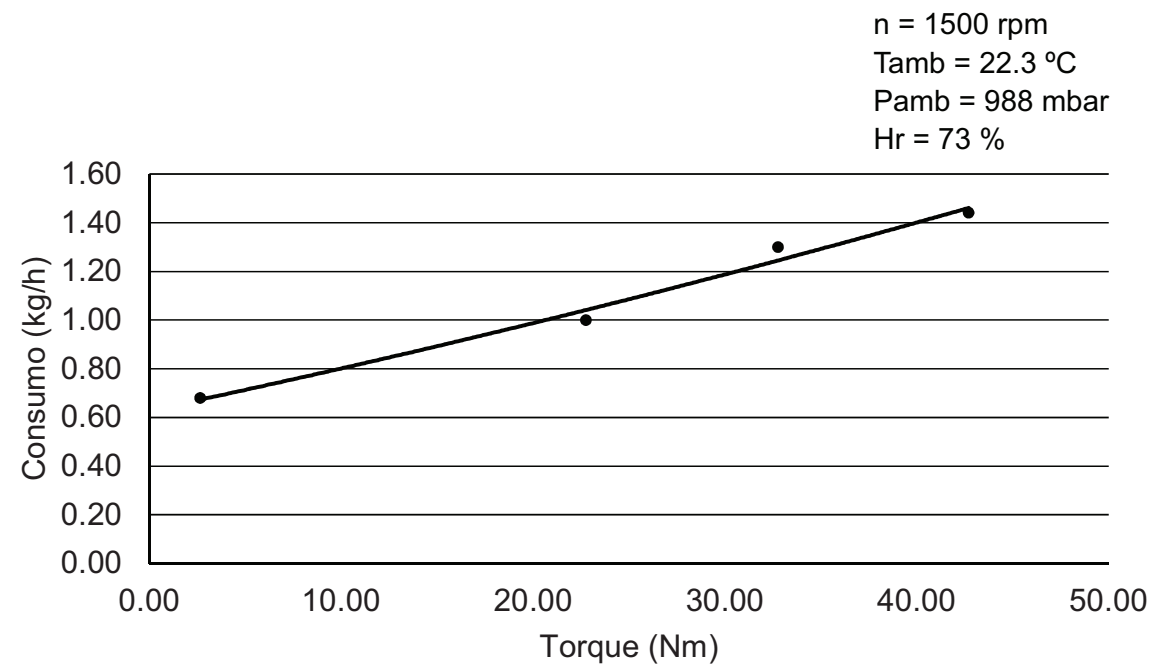

Elaboración propia. 
La segunda curva muestra el consumo de combustible en $\mathrm{kg} / \mathrm{h}$ en función de la potencia efectiva entregada por el eje cigüeñal, en $\mathrm{kW}$. La tendencia del consumo de combustible es de un incremento levemente parabólico.

Figura 10

Consumo versus potencia DB12

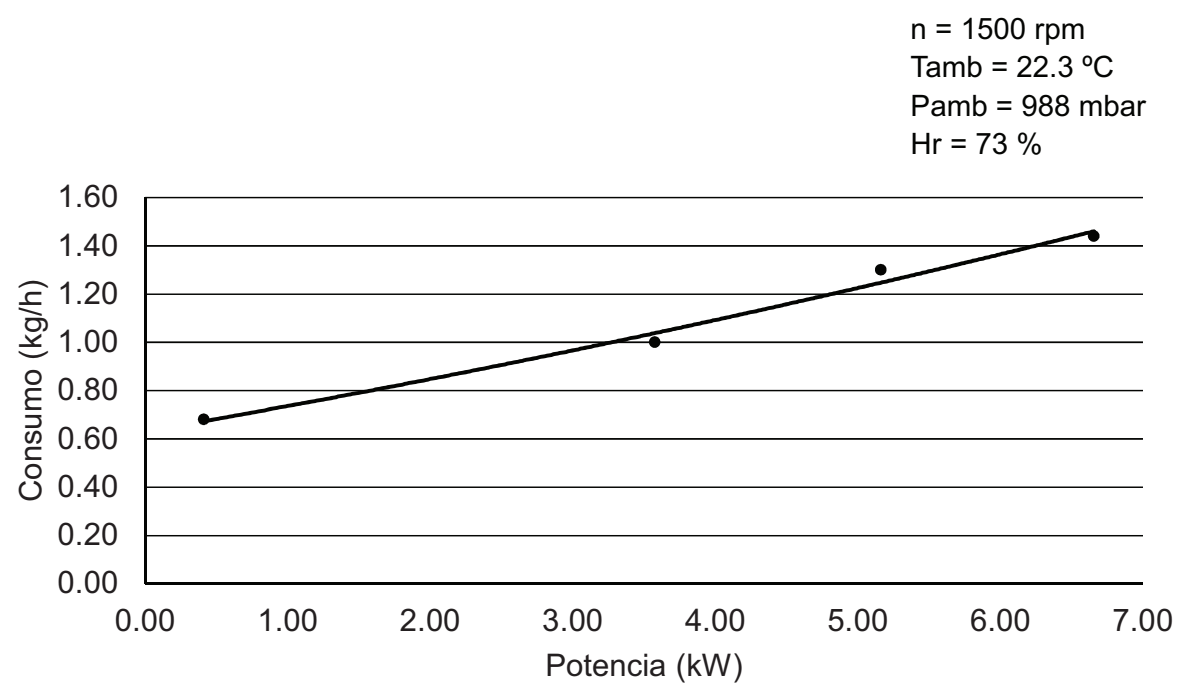

Elaboración propia. 
La tercera curva muestra la eficiencia efectiva del motor en función del torque, con una tendencia hacia el $36 \%$ de eficiencia. Cuando la carga es cero, la eficiencia es cero, pues no se transmite potencia ni torque; pero el motor consume combustible para su funcionamiento.

Figura 11

Eficiencia versus torque DB12

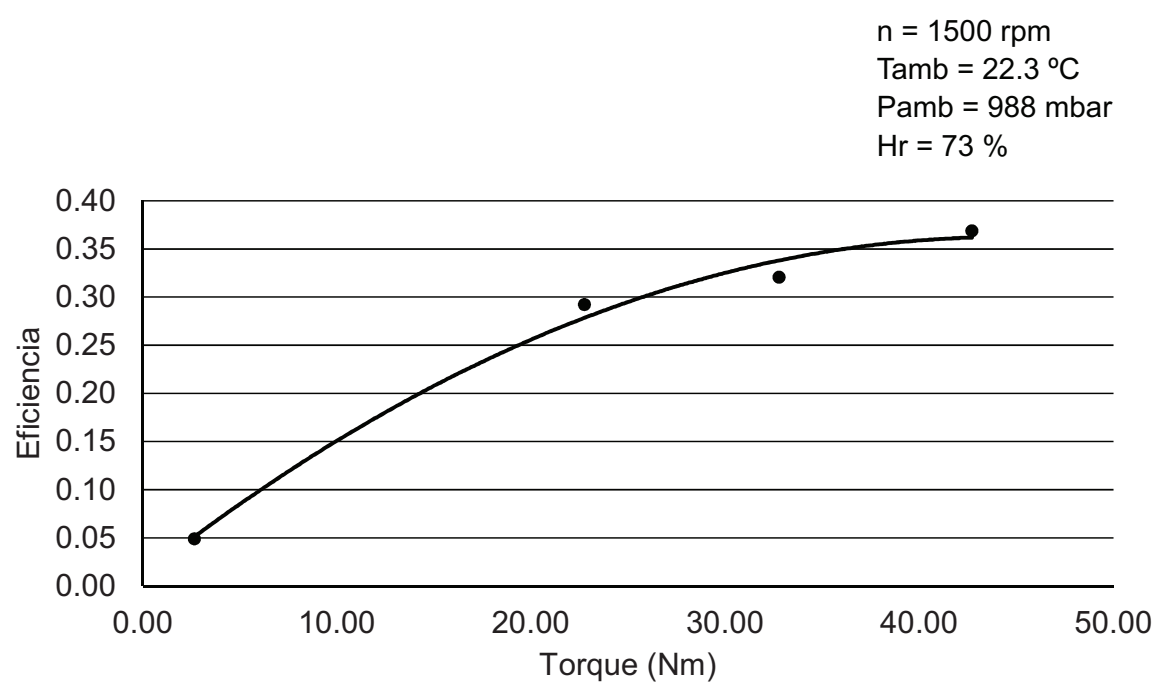

Elaboración propia. 
La cuarta curva representa la tendencia de la eficiencia en función de la potencia; se obtiene un valor máximo de $36 \%$.

Figura 12

Eficiencia versus potencia DB12

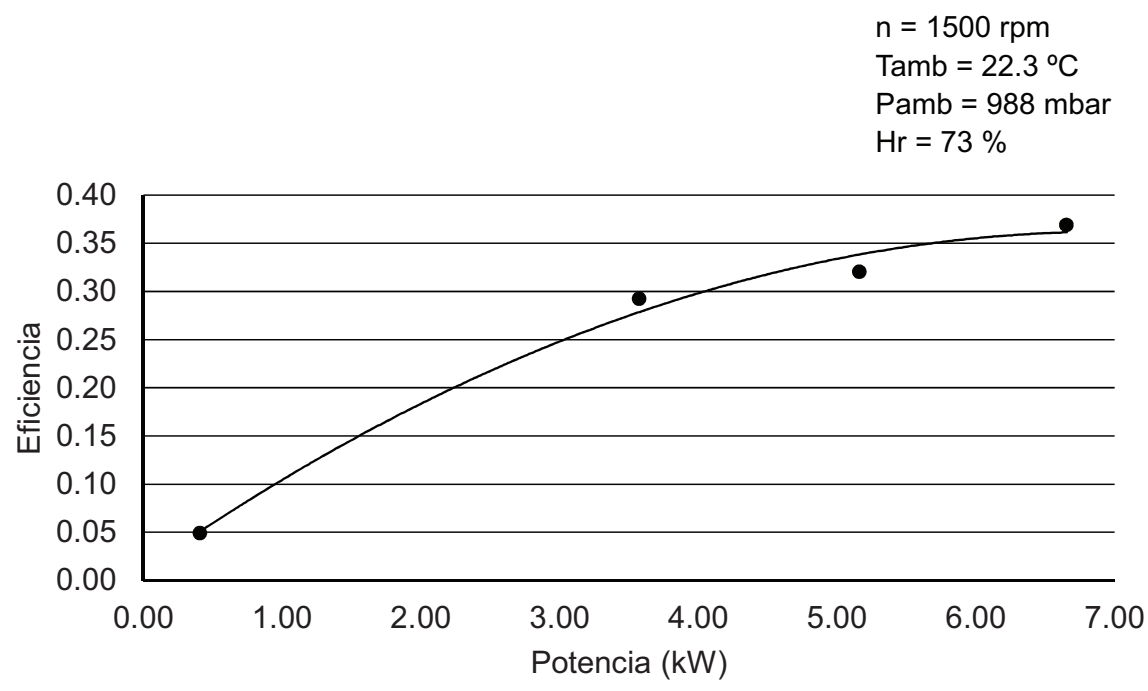

Elaboración propia. 
La quinta curva muestra la eficiencia versus el consumo de combustible, marcando una tendencia logarítmica de eficiencia hacia un valor constante del 36\%. Sin embargo, el consumo de combustible se eleva fuertemente ante el incremento de la carga o torque.

Figura 13

Eficiencia versus consumo DB12

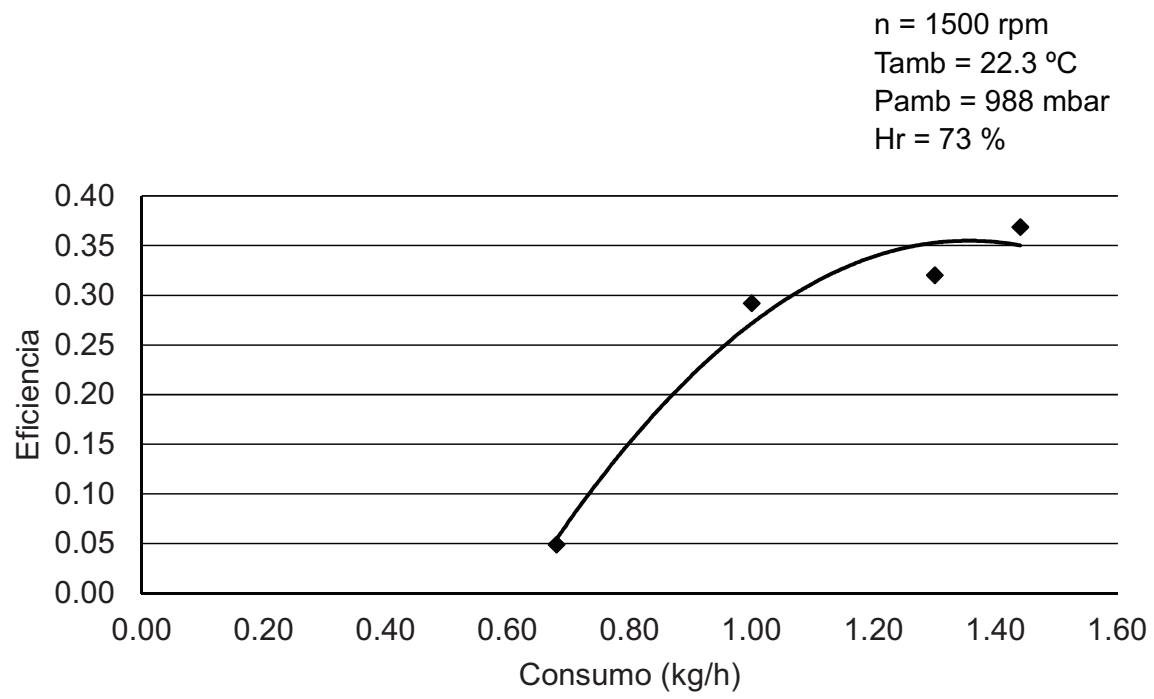

Elaboración propia. 
La sexta curva muestra la eficiencia versus el régimen en rpm, donde se debe vencer solo las pérdidas que originan la turbulencia del aire del giro del freno dinamométrico.

Figura 14

Eficiencia versus régimen DB12

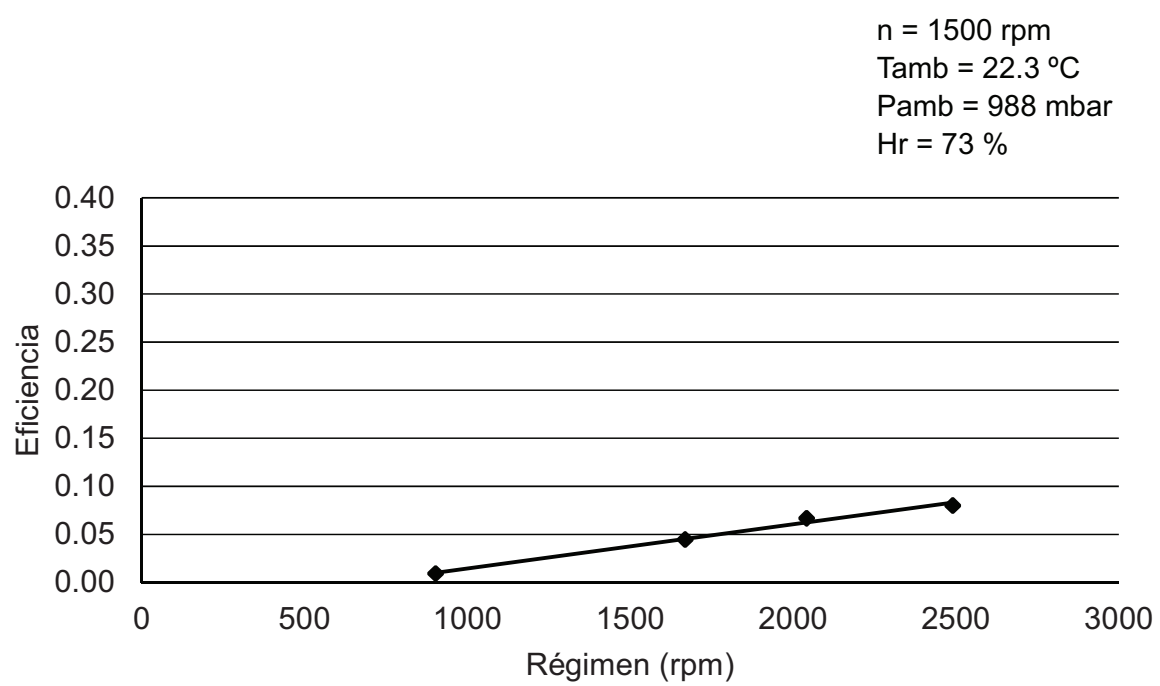

Elaboración propia.

\section{3 Ángulo de adelanto de chispa}

Los motores de ciclo Otto necesitan un tiempo de formación del frente de llama de la mezcla; a mayor octanaje, el tiempo entre la ignición y la explosión será mayor. Cabe considerar que los autos con mayor relación de compresión requieren mayor número de octanos para evitar detonaciones prematuras. Asimismo, al aumentar el régimen, el tiempo de encendido de la mezcla disminuye y por lo tanto es necesario compensar este intervalo de tiempo, adelantando simultáneamente el ángulo de salto de chispa de la bujía. Este trabajo lo realiza en forma electrónica el computador del motor. La figura muestra el ángulo de adelanto de la chispa en función de la velocidad angular del motor para 
la mezcla G95 E12, en la unidad de control activada. A mayor número de revoluciones por minuto del cigüeñal, el adelanto aumenta para dar el tiempo necesario a la producción del frente de llama.

Figura 15

Ángulo de adelanto de la chispa en función de las rpm del eje cigüeñal

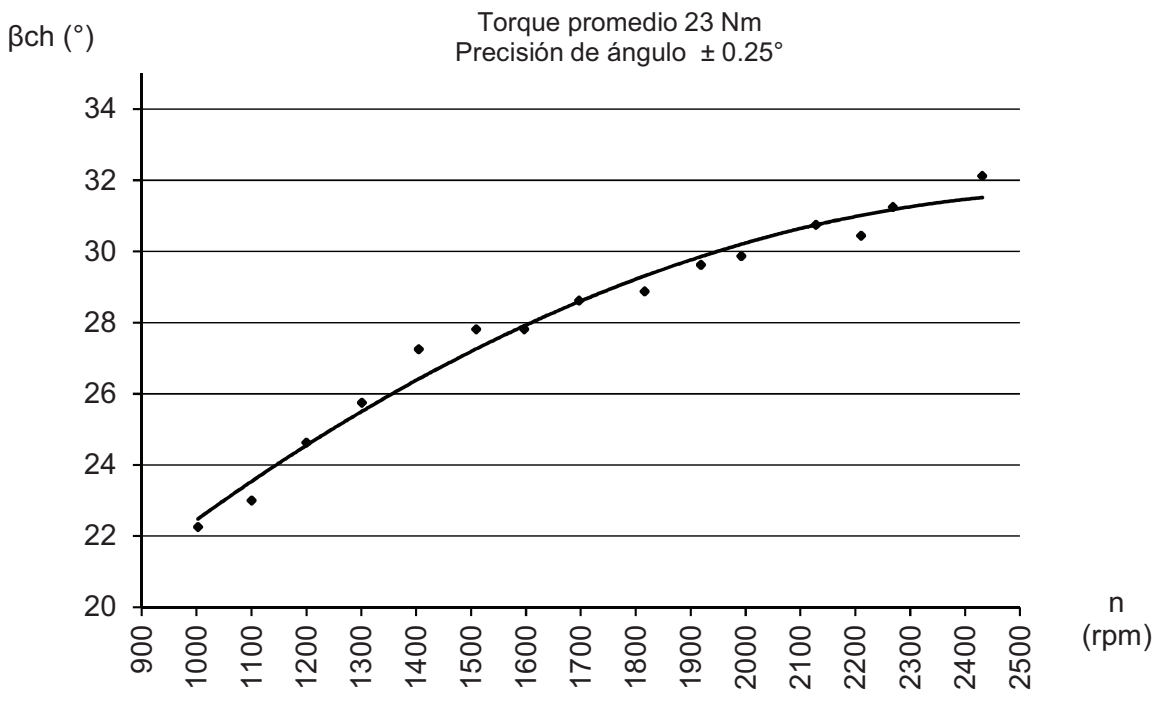

Elaboración propia.

El ángulo $B \mathrm{ch}^{\circ}$ fue tomado con el scanner marca Launch, modelo X-431 GDS (año 2012), utilizado para motores de ciclo Otto, ciclo Diésel, gas e híbridos. 


\section{REFERENCIAS}

Ecopetrol-Cenipalma-Fedepalma. (2012). Pruebas de mezclas diéselbiodiésel en motores de buses y camiones. Recuperado de http:// www.ecopetrol.com.co/especiales/carta_petrolera125/tecnologia. htm

Goñi, J. C. (2009). Máquinas hidráulicas y térmicas. Lima: Universidad de Lima, Fondo Editorial.

GUNT Gerätebau GmbH. (2007). Manual de instrucciones. Alemania.

Ministerio del Ambiente (Minam) (2012). Evolución de emisión de gases de efecto invernadero en Perú. Lima: Minam, Sinaia.

Rojas, M., López, E., \& Zaldívar, S. (2006). Combustibles alternativos para el desarrollo industrial regional. Lima: Universidad de Lima, Fondo Editorial.

US-DOE-Alternative Fuels Data Center. (2012). Fuel Properties Comparison, USA. Recuperado de http://www.afdc.energy.gov/ fuels/biodiesel.html 